\title{
Self medication: need for increased awareness among general population
}

\section{Sir,}

In a recently published study Sugumar $\mathrm{R}$ et $\mathrm{al}^{1}$ evaluated self medication prevalence in primary dysmenorrhea in India. The results of the study prompted me to write regarding drug induced issues with self medication in primary dysmenorrhea and other diseases in general. The results of this study give some insights on the self medication pattern in primary dysmenorrhea among urban Indian women. The authors have highlighted the high prevalence $(42 \%)$ along with inappropriate selfmedication practices in a large number of participants. Inappropriate self-medication practices inadvertently pose the patient to both the risk of lack of efficacy in case of sub-therapeutic dose as well as adverse events in case of excess than recommended dose. Mefenamic acid, a nonsteroidal anti-inflammatory drug (NSAID) or its combination i.e. mefenamic acid + dicyclomine was used by close to one third (35\%) of study population for treatment for primary dysmenorrhea. NSAIDs can cause adverse events; it is important to point out some of the reported findings related respiratory, renal and gastrointestinal safety of mefenamic acid.

Asthma is a worldwide problem. Asthmatic patients have risk of hypersensitivity to aspirin and other NSAIDs. Up to $20 \%$ asthmatic patients are sensitive to aspirin and other NSAIDs. Mefenamic acid cross reacts with aspirin. ${ }^{2}$ The Asthma Epidemiology Study Group in India reported that female sex was associated with significantly higher odds of having asthma. ${ }^{3}$ Secondly, aspirin induced asthma is more common in women. ${ }^{4}$ Considering this, awareness about self medication with mefenamic acid or NSAIDs in patients with primary dysmenorrhea in regards to asthma and related complications is important. Other adverse events of mefenamic acid include nephropathies ${ }^{5}$, and gastrointestinal disturbances.

The study conducted by Sugumar $\mathrm{R}$ et $\mathrm{al}^{1}$ included only urban population and reported high prevalence of self medication. There is a possibility of self medication for primary dysmenorrhea in rural population too, prevalence of which needs to be determined.

The issues are not only with mefenamic acid; other drugs too have their own adverse event profile which needs to be understood by patients before using any drug for selfmedication.
Unknowingly, the patients consuming self-medication expose themselves to the risk of adverse events.

General population needs to understand that apart from dosage, co-morbid diseases, drug interactions, adverse event profile of the drug, risk benefit ratio of the drugs and many other factors are considered while choosing any drug for a patient. As one key does not fit all locks, one drug is not the solution for all patients suffering with same disease.

In light of the high prevalence of self medication and unawareness about the side effects and other associated complications of self medication, there is a need for increasing awareness among general population about the self medication in primary dysmenorrhea and other diseases to avoid drug induced adverse events.

Anant D. Patil*

Freelance consultant: Medical communication and training

*Correspondence to: Dr. Anant D. Patil, Email: anantdpatil@gmail.com

\section{REFERENCES}

1. Sugumar R, Krishnaiah V, Channaveera GS, Mruthyunjaya S. Comparison of the pattern, efficacy, and tolerability of self-medicated drugs in primary dysmenorrhea: A questionnaire based survey. Indian J Pharmacol. 2013; 45:180-183.

2. Suresh Babu K, Salvi SS. Aspirin and Asthma. Chest. 2000; 118:1470-1476.

3. Aggarwal AN, Chaudhry K, Chhabra SK, D'Souza GA, Gupta D, Jindal SK, et al. Prevalence and Risk Factors for Bronchial Asthma in Indian Adults: A Multicentre Study. Indian J Chest Dis Allied Sci 2006;48:13-22.

4. Gohil U, Modan A, Gohil P. Aspirin Induced Asthma- a Review. Global J Pharmacol 2010;4:1930. 
5. Segasothy M, Thyaparan A, Kamal A, Sivalingam S. Mefenamic acid nephropathy. Nephron. 1987;45:156-7. doi:10.5455/2319-2003.ijbcp20131029

Cite this article as: Patil AD. Self medication: need for increased awareness among general population. Int J Basic Clin Pharmacol 2013;2:659-60. 